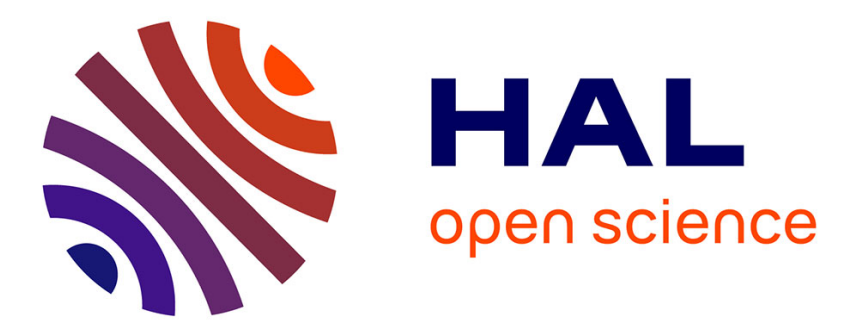

\title{
NONLINEAR OPTICAL PROPERTIES OF SMALL SEMICONDUCTOR PARTICLES
}

\author{
D. Ricard, F. Hache, P. Roussignol, C. Flytzanis
}

\section{To cite this version:}

D. Ricard, F. Hache, P. Roussignol, C. Flytzanis. NONLINEAR OPTICAL PROPERTIES OF SMALL SEMICONDUCTOR PARTICLES. Journal de Physique Colloques, 1988, 49 (C2), pp.C2221-C2-223. 10.1051/jphyscol:1988252 . jpa-00227669

\section{HAL Id: jpa-00227669 https://hal.science/jpa-00227669}

Submitted on 1 Jan 1988

HAL is a multi-disciplinary open access archive for the deposit and dissemination of scientific research documents, whether they are published or not. The documents may come from teaching and research institutions in France or abroad, or from public or private research centers.
L'archive ouverte pluridisciplinaire HAL, est destinée au dépôt et à la diffusion de documents scientifiques de niveau recherche, publiés ou non, émanant des établissements d'enseignement et de recherche français ou étrangers, des laboratoires publics ou privés. 


\title{
NONLINEAR OPTICAL PROPERTIES OF SMALI SEMICONDUCTOR PARTICLES
}

\author{
D. RICARD, F. HACHE, P. ROUSSIGNOL and C. FLYTZANIS \\ Laboratoire d'optique Quantique du CNRS, Ecole Polytechnique. \\ F-91128 Palaiseau Cedex, France
}

Résumé - Nous présentons les résultats de nos études sur les propriétés optiques nonlinéaires de verres commerciaux contenant des microcristaux semiconducteurs ainsi que de nos études préliminaires sur des verres expérimentaux montrant un fort effet de confinement.

Abstract - We present results of our studies of the nonlinear optical properties of commercial semiconductor-doped glasses and of our understanding of their mechanism. Preliminary results obtained on experimental glasses showing a strong quantum confinement effect are also reported.

\section{1 - INTRODUCTION}

Nonlinear optical phenomena such as optical phase conjugation or optical bistability could lead to a large variety of applications in the data processing field. However, the implementation of practical devices strongly depends upon the availability of appropriate nonlinear materials having, among other properties, a large value for $\chi^{(3)}$ and a fast response. With this respect, man-made composite materials such as the semiconductor-doped glasses hold great promise.

Semiconductor-doped glasses, commercially available as color filters, consist of small semiconductor particles embedded in a glass matrix. They were shown to be nonlinear materials as early as $1964^{[1]}$, but really started to be studied as phase conjugating media in $1983^{[2]}$. We report here the results of our thorough study of these commercial glasses. More recently, experimental glasses containing smaller particles have also been investigated.

\section{2 - CFMMERCIALLY AVAILABLE SEMICONDUCTOR-DOPED GLASSES}

Using electron microscopy or small-angle $\mathrm{X}$-ray scattering, we have observed that these glasses such as the Sehott of 570 or RG 610 filters contain spherical particles of cdSSe with an average diameter of 70-80 $\AA$. These particles are not small enough to exhibit a sizeable quantum size effect and their absorption spectra look like those of the corresponding bulk semiconductor.

We have shown that a photochemical process which we termed "darkening"[3] reduces the nonlinear response time (decay time) from tens of nanoseconds to tens of picoseconds or less. Taking advantage of this, a bistable device having a 25 psec response time has been demonstrated bu Yumoto et a] [4]. This darkening effect also leads to the formation of permanent gratings having interesting properties. Owing to darkening and Auger recombination to be discussed below, these glasses are fast response materials.

We also studied the saturation behaviour of the phase-conjugating reflectivity in these glasses and showed how it is related to absorption saturation. Using a tunable dye laser, we have also obser- 
ved that the modulus of the Kerr susceptibility $\chi^{(3)}(\omega,-\omega, \omega)$ is proportional to the absorption coefficient when the operating wavelengt $h$ is varied below, across and above the band gap. We have solved the problem of $\chi^{(3)}$ phase measurements, thus elucidating an apparent sum-rule violation for the tensorial components of $\chi^{(3)}$ and obtaining values for this phase below, across and above the gap.

We have shown that a pulsed excitation of these glasses leads to a blue shift of the absorption edge. This allowed us to interpret almost all the nonlinear optical properties of the commercial glasses in terms of band filling [5]

We have also shown that, at high fluences, Auger recombination of free carriers becomes efficient in the small crystallites. Previously, we had shown that it is necessary to take Auger recombination into account in order to explain absorption saturation and nearly degenerate four-wave mixing data obtained with a Schott RG 715 glass ${ }^{[6]}$ We directly observed the recombination of free carriers in the time domain using two techniques : absorption recovery studied by varying the probe pulse delay in a conventional pump-probe experiment and optical phase conjugation, varying the backward-pump pulse delay in a conventional degenerate four-wave mixing configuration. Since these measurements were performed on a schott OG 570 glass at the wavelength $532 \mathrm{~nm}$, in which case $x^{(3)}$ is imaginary ${ }^{[5]}$, the change in the absorption coefficient $\Delta \alpha$ and the modulus of $\chi^{(3)}$ are proportional, so that the two types of measurements are related. They allow us to study the temporal evolution of $\Delta \mathrm{N}$, the number density of photoexcited carriers.

The results obtained using the optical phase conjugation technique at various fluences (28 psec pulses were used) are shown in figure 1. The decay clearly has a slow and a fast component which we assign respectively to trapped and free carriers. We focus on the fast component which shows a nonexponential and intensity-dependent behaviour. It $c$ an be fit assuming the recombination equation $\frac{d}{d t} \Delta N_{f}=-\frac{1}{\tau} \Delta N_{f}-A\left(\Delta N_{f}\right)^{3}$
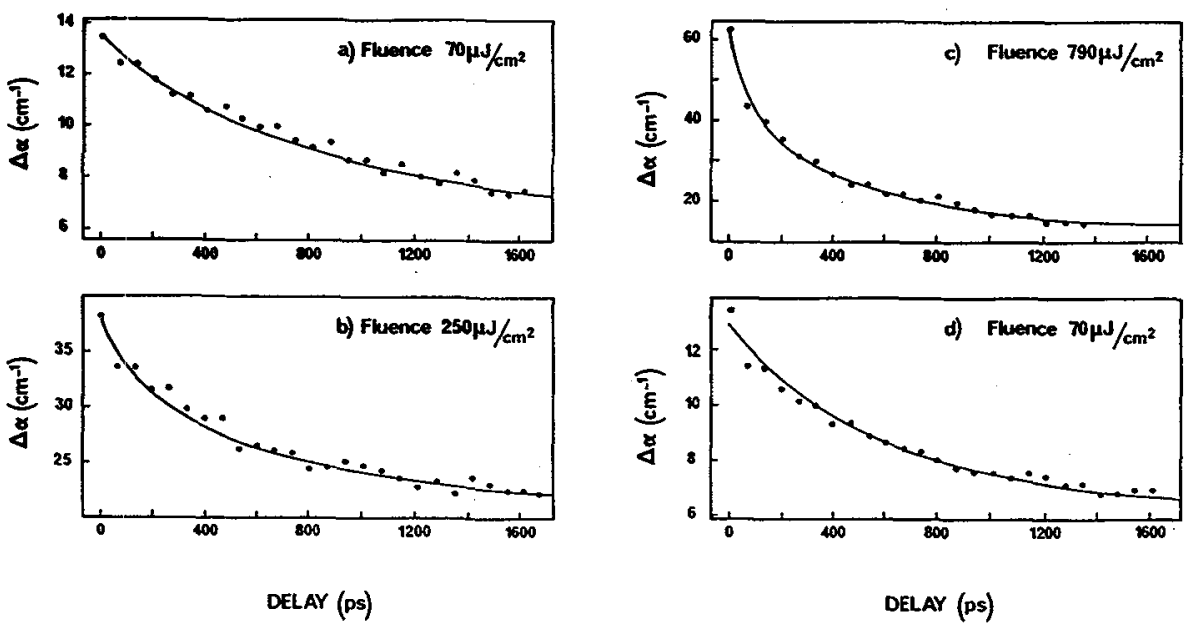

Fig. 1 - Change of the absorption coefficient, calculated from optical phase conjugation data, as a function of the backward pump pulse delay, for various pump fluences. Solid lines are theoretical fits from eq. (1). The fitted time constants $\tau$ are in a) $1.25 \mathrm{~ns}$, b) $1 \mathrm{~ns}$, c) and d) $0.75 \mathrm{~ns}$. 
where the first term is the common Shockley-Read term and the second term corresponds to Auger recombination. (The subscript $f$ stands for fast component). A quadratic term corresponding to nongeminate radiative recombination has been neglected since the recombination process is mainly nonradiative and the excitons are unlikely to be ionized. To fit the experimental data, it is necessary to take into account both the darkening effect, which reduces $\tau$, and the Auger process. The value we get for the Auger constant, $A=5 \times 10^{-26} \mathrm{~cm}^{6} \mathrm{~s}^{-1}$, is the same as the one we obtained in our previous work ${ }^{[6]}$

\section{3 - EXPERIMENTAL SEMICONDUCTOR-DOPED GLASSES}

The mechanism of the optical nonlinearity for commercially available filters containind casse microparticles of 70-80 $\mathrm{A}$ diameter being now reasonably well understood, we recently turned to the study of experimental glasses, with smaller crystaliites. Starting from the melt of a Schott RG 630 glass, we get a transparent glass which is then heat-treated in a temperature gradient. For the higher temperatures, we get the same absorption spectrum as that of the RG 630. For intermediate temperatures, we get smaller particles leading to a blue-shifted and structured absorption spectrum. For still smaller particles, the absorption edge is further shifted, but the structure broadens and we get again a structureless absorption spectrum. The transition between quantized levels therefore seems to broaden when the size is reduced.

Using a picosecond pump pulse at $532 \mathrm{~nm}$, and a white probe pulse, we observed the change in the absorption spectrum induced by a pulsed excitation. The first peak, corresponding to the 1 s-1s transition, when observable, is in the vicinity of $532 \mathrm{~nm}$. This line was usually thought to be inhomogeneously broadened due to size nonuniformity. However, we did not observe any spectral hole burning : the $1 \mathrm{~s}-1 \mathrm{~s}$ band is uniformly saturated. It therefore behaves as a homogeneously broadened transition on our 25 psec timescale. We of course have a size distribution, but the broadening mechanism seems to be mainly intrinsic.

In our previous work on commercial glasses, we observed that $\chi^{(3)}$ is proportional to the absorption coefficient $\alpha$ in a broad frequency range. Preliminary results using optical phase conjugation at a fixed wavelength indicate that in the case of experimental glasses, as the size is reduced and the absorption edge is shifted to the blue, the ratio $x^{(3)} / \alpha$ passes through a maximum when the 1s-1s structure is the most apparent and decreases when the size is further reduced.

\section{References}

[3] - G. Bret and F. Gires Appl. Phys. Lett. 4, 175 (1964)

[2] - R.K. Jain and R.C. Lind J. Opt. Soc. Am. 73, 647 (1983)

[3] - P. Roussignol, D. Ricard, J. Lukasik and C. Flytzanis J. Opt. Soc. Am. B $\underline{4}, 5$ (1987)

[4] - J. Yumoto, S. Fukushima and K. Kubodera Opt. Lett. 12, 832 (1987)

[5] - P. Roussignol, D. Ricard and C. Flytzanis Appl. Phys. A 44,285 (1987)

[6] - F. de Rougemont, R. Frey, P. Roussignol, D. Ricard and C. Flytzanis Appl. Phys. Lett. 50, 1619 (1987) 